\title{
Publisher Correction: Strain Improvement of Native Saccharomyces cerevisiae LN ITCC 8246 Strain Through Protoplast Fusion to Enhance Its Xylose Uptake
}

\author{
Shalley Sharma ${ }^{1} \cdot$ Chandrika Ghoshal $^{2} \cdot$ Anju Arora ${ }^{1} \cdot$ Wara Samar $^{1} \cdot$ Lata Nain $^{1}$. \\ Debarati Paul ${ }^{3}$
}

Published online: 20 April 2021

C Springer Science+Business Media, LLC, part of Springer Nature 2021

\section{Publisher Correction: Applied Biochemistry and Biotechnology} https://doi.org/10.1007/s12010-021-03539-3

The original version of this article unfortunately contained a mistake in the article title. The correct data are shown here. "Protoplasst" should read as "Protoplast." The original article has been corrected.

Publisher's Note Springer Nature remains neutral with regard to jurisdictional claims in published maps and institutional affiliations.

The online version of the original article can be found at https://doi.org/10.1007/s12010-021-03539-3

Shalley Sharma

shalleyss@gmail.com

1 Division of Microbiology, ICAR-Indian Agricultural Research Institute, New Delhi 110012, India

2 Division of Vegetable Science, ICAR-Indian Agricultural Research Institute, New Delhi 110012, India

3 Amity Institute of Biotechnology, Amity University, Noida, Uttar Pradesh 201303, India 